International Journal of Poultry Science 9 (12): 1100-1106, 2010

ISBN 1682-8356

(C) Asian Network for Scientific Information, 2010

\title{
Microsatellite DNA Loci for Population Studies in Brazilian Chicken Ecotypes
}

\author{
C.S. Clementino ${ }^{1,2 \star}$, F.J.V. Barbosa ${ }^{2,3 *}$, A.M.F. Carvalho ${ }^{3}$, R.A.R. Costa-Filho', \\ G.R. Silva ${ }^{1}$, E.G. Campelo ${ }^{1}$, F.B. Britto ${ }^{4}$ and F.M. Diniz ${ }^{5}$ \\ 'Department of Animal Sciences, Federal University of Piauí, Campus Agrícola da Socopo, \\ 64049-550, Teresina, PI, Brazil \\ ${ }^{2}$ RENORBIO Programme from the Brazilian National Research Council, Brazil \\ ${ }^{3}$ Department of Animal Sciences, State University of Piauí, Pirajá, \\ CEP 64002-150, Teresina-PI, Brazil \\ ${ }^{4}$ Department of Natural Sciences, Federal University of Piauí, Campus Cinobelina Elvas, \\ BR 125 Km 3, Planalto Cibrazem, Bom Jesus, PI 64900-000, Brazil \\ ${ }^{5}$ EMBRAPA Meio-Norte, Av. Duque de Caxias, 5650, Cx. Postal: 01, \\ Teresina, PI, CEP: 64.006-220, Brazil
}

\begin{abstract}
In poultry, the reduction in genetic variability of native chicken populations has led to the use of microsatellites in many genetic studies of chicken ecotypes. To be of maximum usefulness as a genetic marker, microsatellite primers should be amplifying the same locus other than the source of the primer sequence in different populations. Even in closely related lines or breeds microsatellite genotyping errors may be introduced from primer mismatches as a result of mutations in the primer binding sites. Therefore, the selection, use and optimization of microsatellites are considered to be a fundamental step towards full success in genetic studies. Herein, 20 microsatellite loci are presented with great potential for diversity studies in Brazilian chicken ecotypes. The analyses of these ecotypes revealed a total of 191 robust alleles, ranging from three to 18 , with an average of 9.6 alleles per locus. The average observed heterozygosity was 0.785 , while the mean expected heterozygosity was 0.688 . Additionally, the mean polymorphic information content value $(0.731)$ further reflected high level of polymorphism across all microsatellite loci. The topology of the dendrogram constructed with the neighbour-joining method showed probable patterns of relationship and genetic differentiation among the individual ecotypes. Overall, microsatellite loci have proven to be highly useful for studying the variability of chicken ecotypes in the Mid-North region of Brazil.
\end{abstract}

Key words: Molecular markers, genetic variability, SSR, local chicken

\section{INTRODUCTION}

Microsatellites are short DNA sequences consisting of tandemly repeated units of 2-6 nucleotides distributed throughout the eukaryotic genome (Diniz et al., 2007). Due to their multiallelic nature, high level of polymorphism, ease of detection by PCR, reproducibility and codominant inheritance, microsatellites are now considered the most used markers for population studies (Zane et al., 2002).

In poultry, the reduction in genetic variability of native chicken populations, with consequent risk of extinction, has led to the use of microsatellites in many genetic studies of chicken ecotypes (FAO, 2000; Mariante and Cavalcante, 2006). The loss of these ecotypes would eliminate unique genetic traits that could be used for future improvement programs and commercial exploitation and therefore, their preservation should be treated as of the highest priority. The Brazilian chicken ecotypes consist of different phenotypes of almost 500 years of natural selection raised by smallholder farmers across distinct agro-ecological regions. To date, however, no investigation has yet been directed towards the use of microsatellite markers to study the genetic variability of these ecotypes, despite the large number of microsatellite primers designed from commercial chicken or database sequences (FAO, 2000).

To be of maximum usefulness as a genetic marker, microsatellite primers should be amplifying the same loci other than the source of the primer sequence in different populations (Kaiser et al., 2000). Even in closely related lines or breeds microsatellite genotyping problems (null alleles, homoplasy, allele dropout) may be introduced from primer mismatches as a result of mutations in the primer binding sites (Pompanon et al., 2005; Soulsbury et al., 2009). Large genetic changes from commercial chicken breeds have been accumulated due to artificial

selection and a wide diversity is known to exist between local and commercial poultry (Tadano et al., 2008). Therefore, the selection, use and optimization of 
microsatellites are considered to be a fundamental step towards full success in genetic studies.

The aim of our study was to select and optimize a set of DNA microsatellites, originally developed from commercial chicken breeds and evaluate their efficacy and informativeness within Brazilian chicken ecotypes inhabiting the Mid-North region of Brazil.

\section{MATERIALS AND METHODS}

Sampling and DNA extraction: Skin tissue samples were collected from Brazilian chicken ecotypes, characterized by high morphological variation, inhabiting the States of Maranhão and Piauí. A tissue fragment of approximately $3 \mathrm{~mm}^{3}$ was removed from the lower part of the chicken wing and stored at $-20^{\circ} \mathrm{C}$ in $100 \%$ ethanol for further analysis. Genomic DNA was extracted using the proteinase $\mathrm{K}$ and phenol/chloroform/isoamyl alcohol method as described in the literature (Sambrook and Russell, 2001). The purified genomic DNA was used as a template for PCR amplification of microsatellite loci as described below.

Microsatellite amplification: A total of 25 microsatellite loci isolated from commercial chicken lines were initially selected based on the degree of polymorphism and genome coverage (Cheng and Crittenden, 1994; Gibbs et al., 1997; McConnell et al., 1999; Crooijmans et al., 1996, 1997). Each microsatellite primer pair was analyzed against a panel of 20 different individuals to verify amplification and optimization of PCR reactions.

PCR conditions: The PCR reaction was carried out in a total volume of $10 \mu \mathrm{L}$ containing $15-30 \mathrm{ng}$ of genomic DNA, 1-1.5 mM MgCl $2,200 \mu \mathrm{M}$ of each dNTP, $0.3 \mu \mathrm{M}$ for each microsatellite primer (forward and reverse), $1.0 \mu \mathrm{L}$ of $10 x$ reaction buffer ( $40 \mathrm{mM}$ Tris- $\mathrm{HCl} ; 100 \mathrm{mM} \mathrm{KCl}), 1$ U Taq DNA polymerase (Invitrogen) and deionized water. The total mixture of PCR reaction was subjected to the gradient thermocycler model Veriti®96-well thermalcycler (Applied Biosystems) under the following conditions: Initial denaturation at $94^{\circ} \mathrm{C}$ for $1 \mathrm{~min}$, followed by 30 cycles of $30 \mathrm{sec}$ at $94^{\circ} \mathrm{C}, 30 \mathrm{sec}$ at annealing temperature of each primer pair and an extension of $50 \mathrm{sec}$ at $72^{\circ} \mathrm{C}$. The final extension was at $72^{\circ} \mathrm{C}$ for $2 \mathrm{~min}$. A two-stage touchdown amplification (Don et al., 1991) profile was designed where specific PCR products were not found. Reactions were conducted with a $1^{\circ} \mathrm{C}$ reduction at each cycle from either $65^{\circ} \mathrm{C}\left(63^{\circ} \mathrm{C}\right)$ to $55^{\circ} \mathrm{C}\left(53^{\circ} \mathrm{C}\right)$, followed by 27 cycles at an annealing temperature of $55^{\circ} \mathrm{C}\left(53^{\circ} \mathrm{C}\right)$ as shown in Table 1.

PAGE electrophoresis: Three to five microliters of the optimized PCR product were mixed with an equal volume of formamide loading dye and pre-heated to $95^{\circ} \mathrm{C}$ for $2 \mathrm{~min}$. Four microliters were separated on a $6 \%$ polyacrylamide gel and silver-stained according to the protocol developed by Benbouza et al. (2006), with the following modifications: fixation solution (20\% ethanol, $0.5 \%$ glacial acetic acid) for $5 \mathrm{~min}$; silver nitrate solution (9 $\mathrm{mM})$ with formaldehyde $(1.5 \mathrm{~mL} / \mathrm{L})$ for $7 \mathrm{~min}$ and developer $(0.37 \mathrm{M} \mathrm{NaOH})$ with formaldehyde $(2.0 \mathrm{~mL} / \mathrm{L})$, or until bands started to appear. The allele size was determined by direct comparison with a 10 bp ladder DNA (Invitrogen). Gel images were scanned for subsequent scoring of allele size.

Data analysis: Allele frequency, number of alleles per locus, allelic richness (a measure of the number of alleles per locus corrected by the sample size), expected $\left(H_{\mathrm{e}}\right)$ and observed heterozygosity $\left(H_{0}\right)$ were computed using the program FSTAT v. 2.9.3 (Goudet, 2001). Deviations from Hardy-Weinberg Equilibrium (HWE) were determined using GENEPOP (Raymond and Rousset, 1995). The Polymorphic Information Content (PIC) was estimated by Cervus version 3.0 (Kalinowski et al., 2007). Distance estimates across individuals were measured using proportion of shared alleles (Dps) calculated on the web-based Genetic Distance Calculator (http://www2.biology.ualberta.ca/jbrzusto/ sharedst.php). The neighbor-joining tree on CavalliSforza and Edward chord genetic distance was constructed using the software PAST v1.34 (Hammer et al., 2001).

\section{RESULTS AND DISCUSSION}

The amplification of microsatellite loci developed from commercial chicken lines was highly successful on the Brazilian chicken ecotypes, which is consistent with the knowledge that microsatellite amplification is inversely related to the genetic distance between species/breeds/ ecotypes (Kuleung et al., 2004). The closer the evolutionary distance is between taxa, the higher the chance of successful amplification.

Of 25 microsatellite primer pairs tested, 80\% successfully amplified the samples collected in the Brazilian Mid-North region, with robust and reproducible bands and easily visualized alleles. The remaining 5 primer pairs (20\%) failed to amplify alleles under all PCR conditions tested. The touchdown PCR technique (Don et al., 1991) was necessary for the optimization of $55 \%$ of microsatellite loci. The annealing temperatures and concentrations of magnesium chloride varied among primer pairs at different loci, as shown in Table 1. At the end, the concentration of each primer, dNTP and Taq polymerase DNA were fixed at $0.33 \mathrm{mM}, 200$ $\mathrm{mM}$ and $0.1 \mathrm{U} / \mu \mathrm{L}$, respectively. 
Int. J. Poult. Sci., 9 (12): 1100-1106, 2010

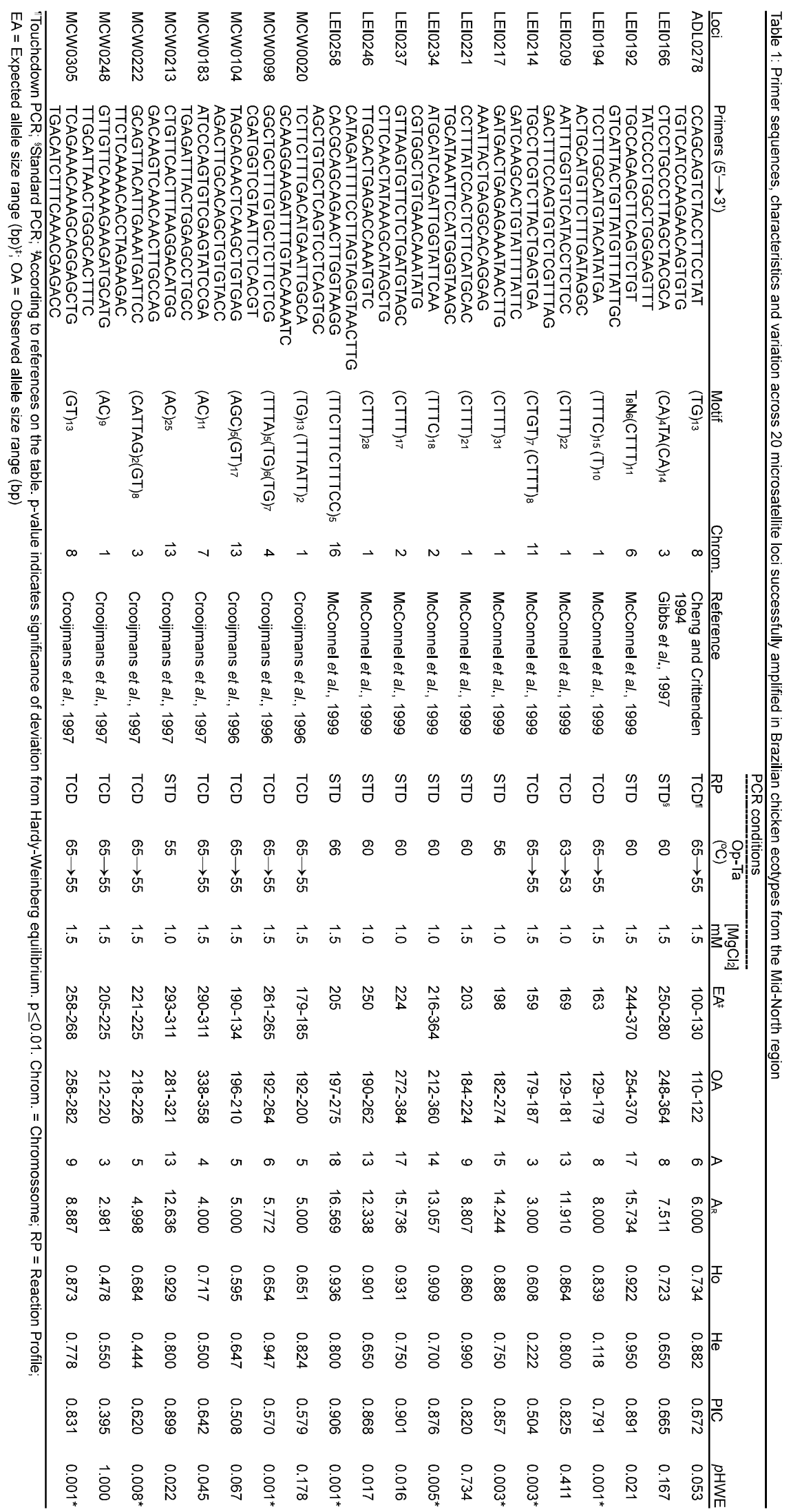


Int. J. Poult. Sci., 9 (12): 1100-1106, 2010

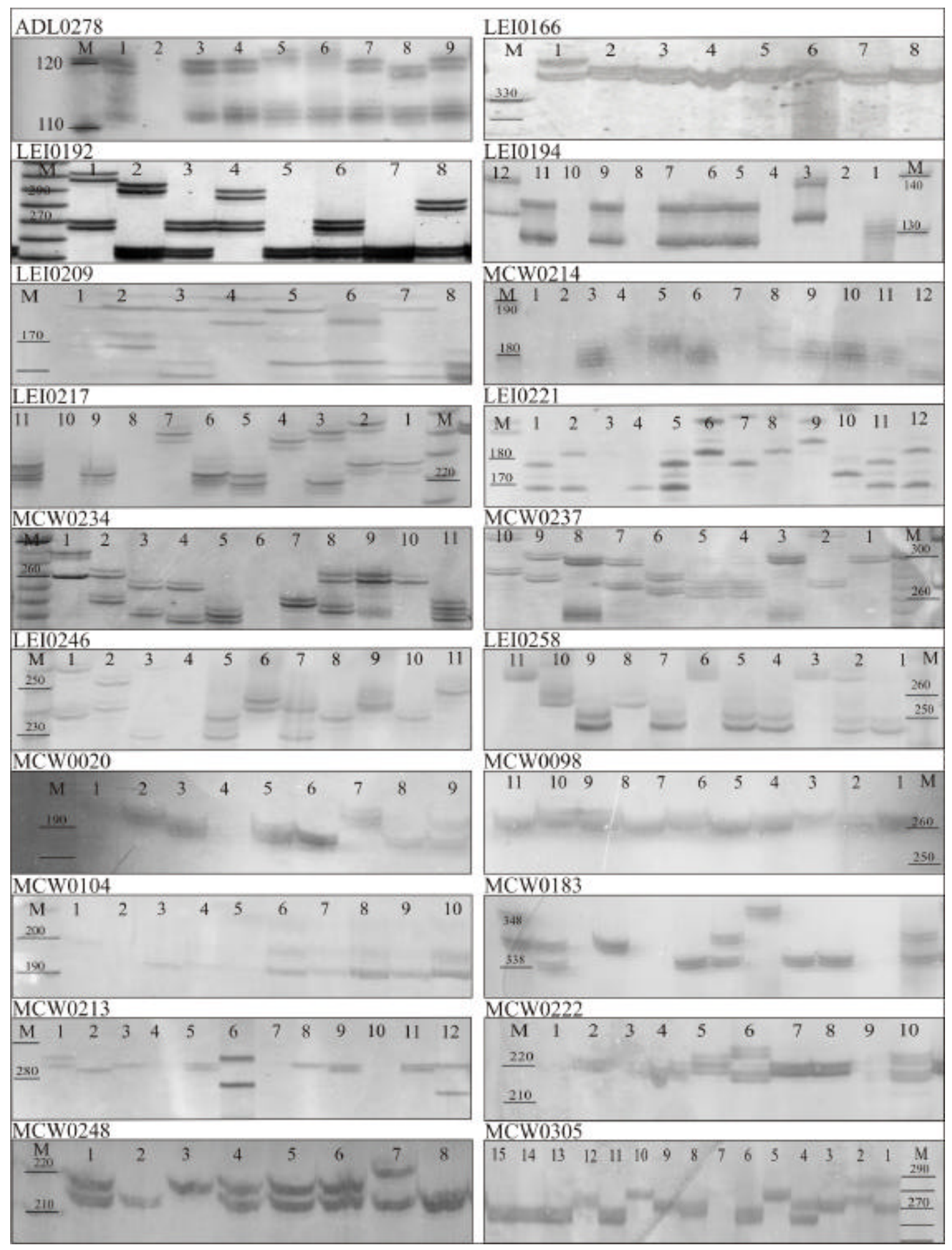

Fig. 1: Silver-stained denaturing polyacrylamide gel electrophoresis of PCR products of 20 SSR markers on ten Brazilian chicken ecotypes. M: 10-bp ladder (Invitrogen)

A total number of 191 alleles were detected in the Brazilian chicken ecotypes. The number of alleles ranged from three (MCW0248 and LEI0214) to 18 (LEI0258), with an average of 9.6 alleles per locus. The 
mean number of alleles in the Brazilian ecotypes was higher than what has been reported for local chickens in Ghana (7.8), Iran (5.4) and China (3.8) (Osei-Amponsah et al., 2010; Mohammadabadi et al., 2010; Liu et al., 2008).

The observed heterozygosity $\left(H_{0}\right)$ was higher than the expected heterozygosity $\left(H_{E}\right)$. The observed heterozygosity for all polymorphic loci varied from 0.478 (MCW0248) to 0.936 (LEI0258) with an average of 0.785 . The expected heterozygosity varied between loci from 0.118 (LEI0194) to 0.990 (LEI0221), with an average of 0.688. These values were comparable to the heterozygosity found in other native breeds (Ethiopian, Iranian, Indian and Chinese) in earlier reports (Hassen et al., 2009; Nasiri et al., 2007; Rajkumar et al., 2008; YaBo et al., 2006).

The mean Polymorphic Information Content (PIC) value (0.731) further reflected high level of polymorphism across all microsatellite loci. PIC values of higher magnitude (0.840) have been reported for Indian native chicken using microsatellite markers, 8 of them similar to those used in our study (Ding et al., 2010). Microsatellites showing PIC values higher than 0.5 indicate that more genetic information can be provided by SSR loci (Botstein et al., 1980). A positive correlation for PICXAR with an $R^{2}$ value of 0.826 shows the close relationship between the two variables.

From all polymorphic loci $40 \%$ showed significant departure from Hardy-Weinberg Equilibrium (HWE), which might be due to the unwitting pooling of populations (Wahlund effect), inbreeding, the presence of null alleles or even an artifact of small sampling size (Lessios, 1992; De La Rua et al., 2001).

The topology of the dendrogram constructed with the neighbour-joining method showed probable patterns of relationship and genetic differentiation among the individuals (Fig. 2). These were grouped in four clusters formed by ecotypes from distinct site collections (i.e. N: Regeneração and T: Teresina in the State of Piauí; B: Brejo and G: Itapecuru-Mirim in the State of Maranhão). A more extensive survey is necessary to obtain a precise picture of the population structure and genetic diversity of these ecotypes inhabiting the Brazil's Mid-North region. No such studies have yet been performed for these local chickens.

Overall, results from this microsatellite survey clearly indicate that all 20 microsatellite markers listed on Table 1 are suitable tools to investigate questions of genetic variability, gene flow and the mating system in Brazilian chicken ecotypes. Further research is being carried out by our group aimed at evaluating genetic variations within this important resource, yet lacking an efficient strategy for its conservation and management.

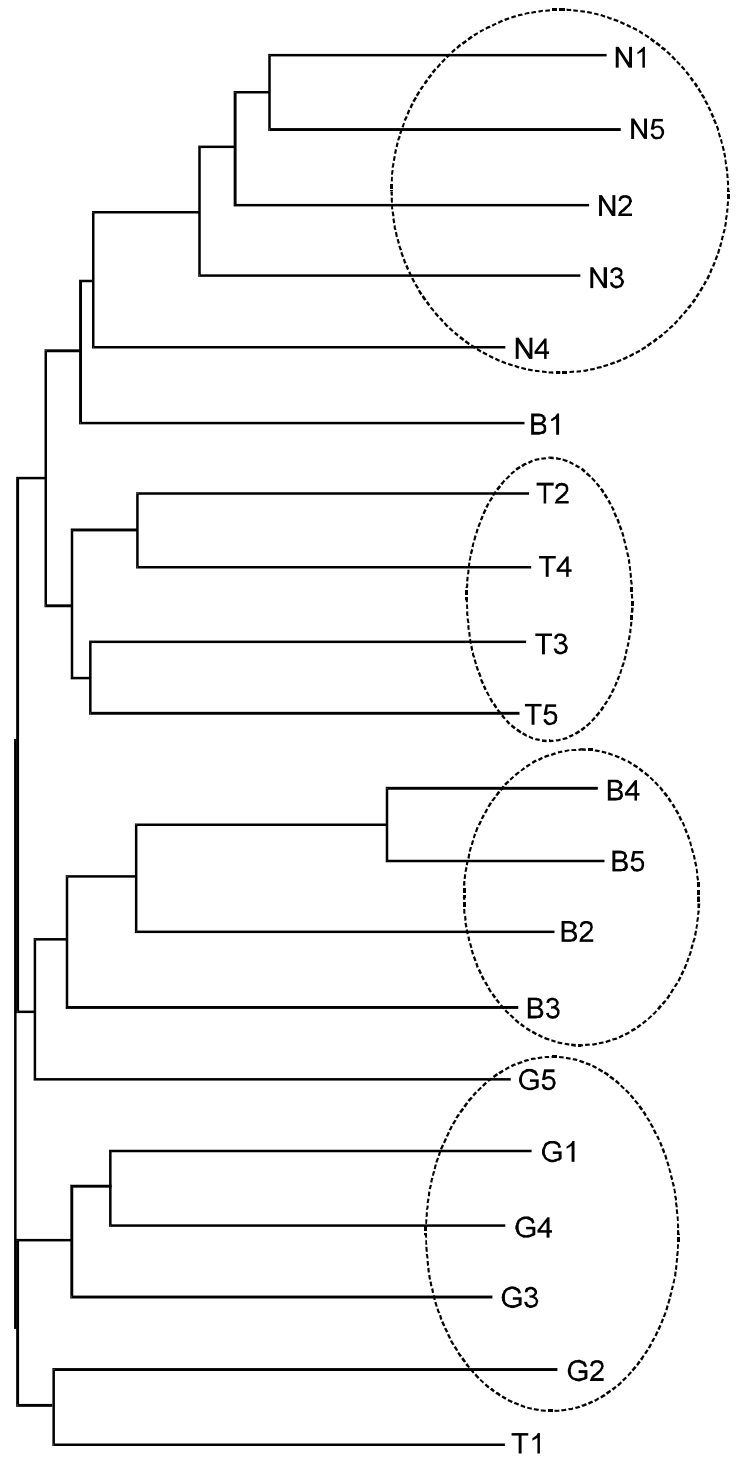

Fig. 2: Neighbour-joining dendrogram of Cavalli-Sforza and Edwards chord genetic distances for microsatellite loci

\section{ACKNOWLEDGEMENTS}

The financial support from BNB/ETENE/FUNDECI (grant No. 97/9531-4) was highly appreciated. This work is part of a thesis presented by F.J.V.B. to the RENORBIO/EMBRAPA in partial fulfillment of the requirements for the $D$.Sc. degree.

\section{REFERENCES}

Benbouza, H., J.M. Jacquemin, J.P. Baudoin and G. Mergeai, 2006. Optimization of reliable, fast, cheap and sensitive silver staining method to detect SSR markers in polyacrylamide gel. Biotech. Agron. Soc. Environ., 10: 77-81. 
Botstein, D., R.L. White, M. Skolnick and R.W. Davis, 1980. Construction of a genetic linkage map in man using fragment length polymorphisms. Am. J. Hum. Genet., 32: 314-331.

Cheng, H.H. and L.B. Crittenden, 1994. Microsatellite markers for genetic mapping in the chicken. Poult. Sci., 73: 539-546.

Crooijmans, R.P., P.A. van Oers, J.A. Strijk, J.J. van der Poel and M.A.M. Groenen, 1996. Preliminary linkage map of the chicken (Gallus domesticus) genome based on microsatellite markers: 77 new markers mapped. Poult. Sci., 75: 746-754.

Crooijmans, R.P., R.J.M. Dijkihof, J.J. van der Poel and M.A.M. Groenen, 1997. New microsatellite marker in chicken optimized for automated fluorescent genotyping. Anim. Genet., 28: 427-437.

De La Rua, P., J. Galian, J. Serrano and R.F.A. Moritz, 2001. Genetic structure and distinctness of Apis mellifera L. populations from the Canary Islands. Mol. Ecol., 10: 1733-1742.

Ding, F.X., G.X. Zhang, J.Y. Wang, Y. Li, L.J. Zhang, Y. Wei, H.H. Wang, L. Zhang and Q.R. Hou, 2010. Genetic diversity of a Chinese native chicken breed, Bian chicken, based on twenty-nine microsatellite markers. Asian-Aust. J. Anim. Sci., 23: 154-161.

Diniz, F.M., A. lyengar, P.S.C. Lima, N. Maclean and P. Bentzen, 2007. Application of a double-enrichment procedure for microsatellite isolation and use of tailed primers for high throughput genotyping. Gen. Mol. Biol., 30: 380-384.

Don, R.H., P.T. Cox, B.J. Wainwright, K. Baker and J.S. Mattick, 1991. Touchdown PCR to circumvent spurious priming during gene amplification. Nucleic Acids Res., 19: 4008.

FAO-Food and Agriculture Organization, 2000. World watch list for domestic animal diversity. 3 Edn., Rome, pp: 744.

Gibbs, M., D.A. Dawson, C. Mccamely, A.F. Wardle, J.A.L. Armour and T. Burk, 1997. Chicken microsatellites marker isolated from libraries enriched for simple sequence repeat. Anim. Genet., 28: 401-417.

Goudet, J., 2001. FSTAT, a program to estimate and test gene diversities and fixation indices (version 293). Updated from Goudet (1995) Available from http://www.unilch/izea/softwares/fstat.html.

Hammer, O., D.A.T. Harper and P.D. Ryan, 2001. PAST: Paleontological statistics software package for education and data analysis. Paleontol. Electron, 4: 1-9.

Hassen, H., F.W.C. Neser, A. de Kock and E van MarleKöster, 2009. Study on the genetic diversity of native chickens in northwest Ethiopia using microsatellite markers. Afr. J. Biotech., 8: 1347-1353.
Kaiser, M.G., N. Yonash, A. Cahaner and S.J. Lamont, 2000. Microsatellite polymorphism between and within broiler populations. Poult. Sci., 79: 626-628.

Kalinowski, S.T., M.L. Taper and T.C. Marshal, 2007. Revising how the computer program CERVUS accommodates genotyping error increases success in paternity assignment. Mol. Ecol., 16: 1099-1106.

Kuleung, C., P.S. Baenziger and I. Dweikat, 2004. Transferability of SSR markers among wheat, rye and triticale. Theor. App. Genet., 108: 1147-1150.

Lessios, H.A., 1992. Testing electrophoretic data for agreement with Hardy-Weinberg expectations. Mar. Biol., 112: 517-523.

Liu, G.Q., X.P. Jiang, J.Y. Wang, Z.Y. Wang, G.Y. Liu and Y.J. Mao, 2008. Analysis of genetic diversity of yangzhou chicken by microsatellite markers. Int. J. Poult. Sci., 7: 1237-1241.

Mariante, A.S. and N. Cavalcante, 2006. Animals of the discovery: Domestic breeds in the history of Brazil, 2 Ed. Brasilia: Embrapa Recursos Genéticos e Biotecnologia, pp: 274.

McConnell, S.K.J., D.A. Dawson, A. Wardle and T. Burke, 1999. The isolation and mapping of 19 tetranucleotide microsatellite markers in the chicken. Anim. Genet., 30: 183-189.

Mohammadabadi, M.R., M. Nikbakhti, H.R. Mirzaee, A. Shandi, D.A. Saghi, M.N. Romanov and I.G. Moiseyeva, 2010. Genetic variability in three native iranian chicken populations of the khorasan province based on microsatellite markers. Russ. J. Genet., 46: 505-509.

Nasiri, M.T.B., F. Shokri, S. Esmaeil Khanian and S. Tavakoli, 2007. Study on polymorphism of Isfahan native chickens population using microsatellite markers. Int. J. Poult. Sci., 6: 835-837.

Osei-Amponsah, R., B.B. Kayang, A. Naazie, Y.D. Osei, I.A.K. Youssao, V.C. Yapi-Gnaore, M. Tixier-Boichard and X. Rognon, 2010. Genetic diversity of Forest and Savannah chicken populations of Ghana as estimated by microsatellite markers. Anim. Sci. J., 81: 297-303.

Pompanon, F., A. Bonin, E. Bellemain and P. Taberlet, 2005. Genotyping errors: Causes, consequences and solutions. Nat. Rev. Genet., 6: 847-849.

Rajkumar, U., B.R. Gupta and A.R. Reddy, 2008. Genomic heterogeneity of chicken populations of India. Asian-Aust. J. Anim. Sci., 21: 1710-1720.

Raymond, M. and F. Rousset, 1995. GENEPOP (version 1.2) Population genetics software for exact tests and ecumenicism. J. Hered., 86: 248-249.

Sambrook, J. and D.W. Russell, 2001. Molecular Cloning: A Laboratory Manual. Cold Spring Harbor Laboratory Press, Cold Spring Harbor, New York. 
Soulsbury, C.D., G. Iossa and K.J. Edwards, 2009. The influence of evolutionary distance between crossspecies microsatellites and primer base-pair composition on allelic dropout rates. Conserv. Genet., 10: 797-802.

Tadano, R., M. Nishibori, Y. Imamura, M. Matsuzaki, K. Kinoshita, M. Mizutani, T. Namikawa and M. Tsudzuki, 2008. High genetic divergence in miniature breeds of Japanese native chickens compared to Red Junglefowl, as revealed by microsatellite analysis. Anim. Genet., 39: 71-8.
Ya-Bo, Y., W. Jin-Yu, D.M. Mekki, T. Qing-Ping, L. HuiFang, G. Rong, G. Qing-Lian, Z. Wen-Qi and C. Kuan-Wei, 2006. Evaluation of genetic diversity and genetic distance between twelve chinese indigenous chicken breeds based on microsatellite markers. Int. J. Poult. Sci., 5: 550-556.

Zane, L., L. Bargelloni and T. Patarnello, 2002. Strategies for microsatellite isolation: A review. Mol. Ecol., 11: 1-16.

*The first two authors contributed equally to this work and should be considered cofirst authors. 